\title{
Doğadan Toplanan Festuca valesiaca L. Genotiplerinde Morfolojik Farklılığın Belirlenmesi
}

\author{
Damla Pınar ${ }^{*}$, Mehmet Ali Avc1² \\ Geliş / Received: 17/12/2019 \\ Revize / Revised: 30/12/2019 \\ Kabul / Accepted: 31/12/2019
}

\section{ÖZ}

Çalışmada kullanılan materyaller 1130919 no' lu TÜBİTAK projesinden elde edilmiştir. Projede 530 civarında Festuca valesiaca genotipi toplanmıştır. Materyaller fide halinde 2015 yılı Temmuz-Ağustos ayları içerisinde $0.5 \mathrm{~m}$ x $0.5 \mathrm{~m}$ aralıklarla S.Ü. Ziraat Fakültesi deneme tarlasına dikilmiştir. Deneme gözlem ve ölçümleri 2016 2017 vejetasyon döneminde alınmıştır. Doğadan toplanmış olan meşe yumağı (Festuca valesiaca $\mathrm{L}$.) genotiplerin de yeşil alan ve yem bitkisi olarak kullanılabilirlik bakımından belirli tarımsal özellikleri belirlenip ve bu özellikler doğrultusunda üstün olan genotiplerden 50 adedi seçilmiştir. Çalışma sonucunda, Festuca valesiaca'nın çim kalitesi 6.73; mevsimsel renk değişimi 5.08; yaprak dokusu 2.89; yoğunluk 5.39; bitki boyu $26.70 \mathrm{~cm}$; yaprak eni $0.22 \mathrm{~cm}$; yaprak boyu $6.15 \mathrm{~cm}$; sonbaharda büyüme şekli 4.74; bitki çapı $11.49 \mathrm{~cm}$; ilkbaharda büyüme zamanı 5.10; salkım oluşturma eğilimi 4.15; salkım boyu $5.81 \mathrm{~cm}$; son boğum uzunluğu $17.68 \mathrm{~cm}$; yeşil ot verimi skalası 3.57 olarak belirlenmiştir. Elde edilen bu veriler değerlendirilip, bu bitkilerin mera ve yem bitkileri tarımında ayrıca yeşil alan tesisinde kullanılabilme potansiyelleri ortaya konularak ve sslah çalışmaları için temel verileri belli olan genetik materyaller elde edilmiştir. Çalışmada elde edilen sonuçlar geniş coğrafik yapıya sahip bölgelerde mevcut varyasyonun kullanılması ile genetik tabanı genişletmek ve mevcut varyasyonun boyutunu öğrenmek ıslah çalışmalarında gerekli olduğunu göstermektedir. Ayrıca bu çalışmanın ileride yapılacak benzer karakterizasyon, seleksiyon ve islah çalışmalarına önemli katkı sağlayacağı düşünülmektedir.

\footnotetext{
1*Sorumlu yazar iletişim: damlapinar52@gmail.com (https://orcid.org/0000-0002-0107-9772)

Tarla Bitkileri Bölümü, Ziraat Fakültesi, Selçuk Üniversitesi, KONYA.

2İletişim: mavci@selcuk.edu.tr (https://orcid.org/0000-0003-2448-8779)

Tarla Bitkileri Bölümü, Ziraat Fakültesi, Selçuk Üniversitesi, KONYA.
} 


\title{
Determination of Morphological Diversity in Festuca valesiaca $\mathrm{L}$. Genotypes Collected from the Nature
}

\begin{abstract}
The materials used in the study were obtained from TUBITAK project number 1130919. Around 530 Festuca valesiaca genotypes were collected in the project. Materials in seedlings in July-August $20150.5 \mathrm{~m} \mathrm{x} 0.5 \mathrm{~m}$ intervals in S.Ü. Faculty of Agriculture was planted in the trial field. Experimental observations and measurements were taken in 2016-2017 vegetation period. Oak fescue (Festuca valesiaca L.) genotypes collected from nature were determined in terms of usability as green field and forage crops and 50 of these genotypes were selected according to these characteristics. As a result of the study, the grass quality of Festuca valesiaca is 6.73; seasonal color change 5.08; leaf texture 2.89; density 5.39; plant height $26.70 \mathrm{~cm}$; leaf width $0.22 \mathrm{~cm}$; leaf height $6.15 \mathrm{~cm}$; growth in autumn 4.74; plant diameter $11.49 \mathrm{~cm}$; growth time in spring 5.10; cluster tendency 4.15 ; cluster length $5.81 \mathrm{~cm}$; last internode length $17.68 \mathrm{~cm}$; green grass yield scale was determined as 3.57 . By evaluating these data, the potential of these plants to be used in pasture and forage crops agriculture and green field facility were revealed and genetic materials with basic data for breeding studies were obtained. The results obtained in this study show that it is necessary to improve the genetic base by using the existing variation in regions with large geographical structure and to learn the extent of the existing variation in breeding studies. In addition, this study is thought to make a significant contribution to future characterization, selection and breeding studies.
\end{abstract}

Keywords- Grass Quality, Oak Fescue, Morphological Characteristics

NOT: Bu çalışma Damla Pınar tarafından Selçuk Üniversitesi Fen Bilimleri Enstitüsü Tarla Bitkileri Anabilim Dalında yapılan yüksek lisans tezinin bir kısmını kapsamaktadır. 


\section{GíRIŞ}

Genetik çeşitlilik ve gen kaynakları yönünden ülkemiz oldukça zengindir. Çevresel ve diğer faktörler yönünden gen kaynaklarımız erozyona uğramakta ve yok olma tehlikesi yaşamaktadır. Özellikle, tarımı yapılan türlere ait bitki genetik kaynaklarındaki çeşitliliğin korunması, bitkisel üretimin devamlılığı bakımından önemlidir. Ülkemiz doğal florası pek çok buğdaygil yem bitkisinde olduğu gibi yumak genotiplerince de zengin bir çeşitliliğe sahiptir [1].

Bölgenin florasının bilinmesi bir bölgede doğal vejetasyonun korunması ve geliştirilmesi, bitki sslah materyalinin sağlanması ve çeşitlendirilmesi, bitki gen kaynaklarının korunması gibi bilimsel çalışmaların sürdürülebilmesi için gereklidir [2]. İleri de gerekli olduğunda geçmişte var olan kaynakların bulunamama ihtimali oldukça yükssektir. Böyle durumlar karşısında, doğal floramızda bulunan çim bitkilerini kullanarak yeni çeşitler ıslah etmemiz ve gen kaynaklarımızı kendimize kullanarak ekonomiye katkı ve değer kazandırmamız gerekmektedir [3].

Orta Anadolu Bölgesi de yıllardan beri sürdürülen aşırı otlatma ve bilinçsiz kullanım çayır - mera vejetasyonlarında bulunan arzulanan türlerin yok olmasına ve biyolojik çeşitliliğin hızlı bir şekilde daralmasına neden olmaktadır, Bu sorun ülkemizde de aynı durumdadır. Yerli genotipler; aşırı otlatma, çayır ve meraların tarıma açılması gibi etkilerin yanı sıra, yerleşim alanlarına dönüştürülmesi ve çevresel kirlenme sonucunda yok olma tehlikesi ile karşılaşmaktadır. Ülkemizin iklim koşullarına iyi adapte olamayan yabancı çeşitler yok olmaktadır. Ülkemizde çayır meraların bir kısmında bitki örtüsü önemli ölçüde azalmış, bu alanlar erozyona açık duruma gelmişlerdir. Diğer bir kısım çayır - mera alanlarında da kaliteli otlar az miktarda bulunmakta, mevcut bitkilerin çoğunluğunu yabancı ot karakterinde ve hayvanlar tarafından değerlendirilmeyen otlar oluşturmaktadır. Doğal yapının bozulmuş olması mera durumunu tehdit etmektedir. Buna karşılık yem bitkileri tarımında ve çayırmera 1slahında kullanılabilecek doğal vejetasyondan seçilip çoğaltılmış ve test edilmiş bitki materyali yoktur. Bunun için doğal florada bulunan yem bitkisi türlerinin belirlenmesi ve uygunluğunun tespit edilmesi şarttır [4]. Dış mekanların önemli bir bölümünü oluşturan yeşil alan bitkileri mimari ve estetik açıdan kullanılmakta ve insanın gereksinim duyduğu dinlenme ortamını sağlamaktadır. Bu bitkilerin tohumları ithal edilmekte ve önemli döviz kaybı olmaktadır. Kuzey Avrupa ve Kuzey Amerika'da 1slah edilmiş çeşitlerin bölgemiz ekolojisine, var olan hastalık ve zararlıların tür ve ırklarına yeterince dayanıklı olmaması, kuruluş ve bakım masraflarını artırmaktadır. Yıl boyu çim kalitesini koruyabilmek için bu yabancı çeşitler gübreleme, sulama, hastalık ve zararlılarla mücadele gerektirmekte ve yeşil alan maliyetini bir hayli yükseltmektedir. Ülkemizde her bölgeye ve amaca uygun çim türleri açısından kendi doğal kaynaklarını değerlendirerek özgün çim çeşitlerini geliştirecek çalışmalar oldukça azınlıktadır [5].

Ülkemizde bu tür konular ile yeterli araştırmacı, araştırma ve yayın bulunmamaktadır. Bu çalışmamızda hem yeşil alan hem de yem bitkisi amacı ile doğadan toplanmış olan yumak materyalleri ıslah çalışmalarına alt yapı niteliğinde bir çalışma olduğu için yukarıda bahsedilen sorunların çözümüne yarar sağlayacaktır.

Bu sorunların çözümünde ise önemli bir yere sahip olan Festuca cinsi Dünyada yaklaşı 450 tür ve alt türü bulunurken ülkemizde ise doğal olarak 52 adet türü dağılım göstermektedir.

\section{MATERYAL VE YÖNTEM}

Çalışmada kullanılacak materyaller, Mehmet Ali AVCI tarafından yürütülen TÜBİTAK 1130919 nolu "Doğal florada bulunan çim ve yem olarak kullanılabilecek bazı buğdaygil yem bitkilerinin toplanması ve 1slah amaçlı Kullanılması" adlı proje kapsamında, 2014 yılının Nisan - Temmuz ayları arasında toplanan 530 adet Festuca valesiaca türüne ait bitkilerden seçilen 50 adet genotipi kapsamaktadır. Hem köklü bitki hem de tohum olarak toplanmış olan yumak genotipleri 16 farklı ilden (Ankara, Çankırı, Çorum, Yozgat, Eskişehir, Afyon, Konya, Aksaray, Niğde, Karaman, Kırşehir, Kayseri, Kırıkkale, Sivas, Mersin ve Antalya) toplanmııstır.

Doğadan tohum olarak toplanmış olan bitkiler serada saksılara ekilerek, köklü bitki olarak toplanmış olanlar ise saksılara dikilerek gelişmeleri sağlanmıştır. Sera şartlarında, yeterince büyüme gösteren genotipler fide halinde 2015 Temmuz-Ağustos aylarında araziye şaşırtılmıştır.

Materyaller fide halinde 2015 yılı Temmuz-Ağustos ayları içerisinde $0.5 \mathrm{~m}$ x $0.5 \mathrm{~m}$ aralıklarla S.Ü. Ziraat 
Fakültesi deneme tarlasına dikilmiştir. Bitkiler salkım oluşturdukları zaman tür ve alttür ayrımları yapılmıştır. Dikim yapılmış olan bitkiler için sulama, gübreleme, yabancı ot mücadelesi ve biçim gibi normal çim bakım teknikleri düzenli olarak uygulanmıştır.

Arazide bulunan bu bitkilerde çim ve yem bitkisi olmak üzere iki amaca yönelik bitkisel ve tarımsal özellikler incelenmiştir. Gözlem ve ölçümler 2016-2017 yıllarında alınmıştır. Yapılan ölçüm ve gözlemler International Union for The Protection Of New Varieties Of Plants (UPOV) kriterleri Tamkoç ve arkadaşlarının [6-7], kullandığı yöntemler esas alınarak uygulanmıştır.

\section{Araştırmada yapılan gözlem ve ölçümler}

1- Çim kalitesi (1-9 skalası): Çim kalitesi renk, yoğunluk, üniformite, doku (tekstür), hastalık ya da çevresel streslere tepkimesinin bir kombinasyonu görsel olarak değerlendirilmiştir. Skala değerleri: $1=$ En zayıf/kötü, 6= Kabul edilebilir, 9= Üstün veya ideal

2- Mevsimsel Renk Değişimi (1-9 skalası): Bitkilerin renkleri belirlenirken mevsimlere göre ayrı ayrı belirlenmiştir. İlkbahar ve sonbaharda, yaz ve kış dönemlerinde renk gözlem ve ölçümleri yapılmıştır. Mevsimsel renk hastalık ya da böceklerin zararlarını, besin maddelerinin eksikliği yada çevresel streslere bağlı olarak renk farklılıklarını başarılı bir şekilde ayırt etmede kullanılabilmektedir. Rengini muhafaza edebilme; mevsim değiştikçe rengini koruyabilme kabiliyetidir. Görsel olarak 1-9 skalası kullanılarak ve skala değerleri:1= Saman sarıs1-kahverengi, 9= Koyu yeşil olarak değerlendirilmiştir.

3- Yaprak Dokusu (1-9 skalası): Yaprak dokusu, yaprak genişliğinin görsel ölçümüdür. Değerlendirme salkım teşkil edebilecek bir gövdenin gelişmiş yaprağı dikkate alınarak yapılmıştır. Skala değerleri 1= Dar/narin, 5= Orta 9=Geniş/kaba olarak değerlendirilmiştir.

4- Yoğunluk (1-9 skalası): Çim yoğunluğu birim alandaki sürgün miktarının görsel olarak tahmin edilmesidir. Sürgün yoğunluğu yılın farklı zamanlarına göre değişir. Yoğunluk gözlemleri, ilkbahar, yaz ve sonbaharda yapılarak iklimsel farklılıklar gözlemlenir. Görsel olarak 1-9 skalası kullanılır: 1= Çok seyrek, 3= Seyrek, 5= Orta, $7=$ Sık, 9= Çok sık olarak değerlendirilmiştir

5- Salkım Oluşturma Eğilimi (1-9 skalası): Bitkilerde en az üç salkım görüldüğünde her bir genotip kaydedilmiştir. Skala değerleri:1= Yok ya da zayıf, 3= Zayıf, 5= Orta, 7= Güçlü, 9= En Güçlü

6- Sonbaharda Büyüme Şekli: Sonbaharda büyüme şekli ekim yılında gözlemlenmiştir. Gözlemler bitki habitusunun toprak yüzeyi ile yaptığı açı dikkate alınmıştır. Skala değerleri: 1= Dik, 3= Yarı dik, 5= Orta, 7= Yarı yatık, $9=$ Yatık

7- Bitki Boyu (cm): Gelişmesini tamamlamış en az 3 sapta alınarak bitki boyu, sapların toprak yüzeyi ile en uç noktası arası arasındaki mesafenin cm cinsinden ölçülmesi ile bulunmuştur.

8- Yaprak Eni (mm): Bitki boyu ölçülen saplarda gelişmesini tamamlamış yaprağın eni ölçülerek mm cinsinden kaydedilmiştir.

9- Yaprak Boyu (cm): Yaprak eni ölçülen yaprakların yaprak boyu da cetvel yardımıyla ölçülerek $\mathrm{cm}$ cinsinden kaydedilmiştir.

10- Yaprak alanı $\left(\mathrm{cm}^{2}\right)$ : Yaprak eni ve boyunun çarpımı sonucunda $\mathrm{cm}^{2}$ cinsinden hesaplanmıştır.

11-Salkım Boyu (cm): Her bir genotip için bitki boyu ölçülen 3 sapta, salkım üzerindeki en altındaki başakçığın çıktığı yer ile en üstteki başakçığın arasındaki mesafe cm cinsinden ölçülerek belirlenmiştir.

12-Son Boğum Uzunluğu (cm): Bitki boyu ölçülen sapların, bayrak yaprağın çıktığı boğumdan ilk başakcığın çıktığı yere kadar olan mesafenin cm cinsinden ölçülmesi ile tespit edilmiştir.

13- 1000 Tohum Ağırlığı (g): Her bitkiden ayrı ayrı edilen tohumlardan sağlam olanların 4 x 100 şeklinde 
sayılması, ortalamalarının alınması ve 10 ile çarpılması sureti ile hesap edilmiştir.

14- Yeşil Ot Verimi (1-9 skalası): Çiçeklenme başlangıcında (otlatma olgunluğuna geldiği zaman) görsel olarak 1-9 skalası kullanılarak her genotip için belirlenmiştir. 1= En düşük sürgün, 5= Orta, 9= En yüksek (ot tipi)

\section{ARAŞTIRMA SONUÇLARI VE TARTIŞMA}

Doğadan toplanmış Festuca valesiaca ya ait genotiplerde, 2016-2017 yıllarında incelenen morfolojik ve tarımsal özelliklere ilişkin ortalama, en küçük, en büyük, standart sapma (SD) ve değişim katsayıları (CV) Tablo 1' de gösterilmiştir.

Tablo 1. Festuca valesiaca Genotiplerinden Alınan Bazı Özelliklerin Ortalama, En Küçük, En Yüksek, Standart Sapma (SD) ve değişim katsayısı (CV) değerleri

\begin{tabular}{|c|c|c|c|c|c|c|}
\hline Özellikler & Örnek sayısı & Ortalama & En yüksek & En düşük & SD & $\mathrm{CV}(\%)$ \\
\hline Çim Kalitesi & 50 Adet & 6.73 & 9.00 & 4.00 & 0.90 & 13.43 \\
\hline Mevsimsel renk değişimi & 50 Adet & 5.08 & 9.00 & 1.00 & 1.43 & 28.12 \\
\hline Yaprak dokusu & 50 Adet & 2.89 & 8.00 & 1.00 & 1.36 & 47.08 \\
\hline Yoğunluk & 50 Adet & 5.39 & 8.00 & 1.00 & 1.41 & 26.17 \\
\hline Salkım oluşturma eğilimi & 50 Adet & 26.70 & 73.00 & 3.00 & 13.62 & 51.02 \\
\hline Sonbaharda büyüme şekli & 50 Adet & 0.22 & 3.00 & 0.01 & 0.18 & 81.37 \\
\hline Bitki boyu $(\mathrm{cm})$ & 50 Adet & 6.15 & 17.00 & 0.10 & 2.99 & 48.70 \\
\hline Yaprak eni (mm) & 50 Adet & 4.74 & 9.00 & 1.00 & 1.84 & 38.90 \\
\hline Yaprak boyu $(\mathrm{cm})$ & 50 Adet & 11.49 & 47.00 & 0.50 & 5.70 & 49.56 \\
\hline Salkım boyu $(\mathrm{cm})$ & 50 Adet & 5.10 & 9.00 & 1.00 & 1.83 & 35.91 \\
\hline Son Boğum Uzun. (cm) & 50 Adet & 4.15 & 9.00 & 1.00 & 2.39 & 57.63 \\
\hline 1000 tohum ağırlığ & 50 Adet & 17.68 & 42.00 & 5.00 & 6.71 & 37.93 \\
\hline Yeşil ot verimi & 50 Adet & 3.57 & 8.87 & 2.20 & 0.88 & 124.34 \\
\hline
\end{tabular}

Ölçümü yapılan 50 adet Festuca valesiaca genotiplerinde yapılan gözlem ve ölçümler Tablo 1.' de verilmiştir. Tablo 1.' in incelenmesinde görüldüğü gibi ortalama değerler şöyledir. Çim kalitesi 6,73; mevsimsel renk değişimi 5,08; yaprak dokusu 2,89; yoğunluk 5,39; bitki boyu 26,70 cm; yaprak eni $0,22 \mathrm{~cm}$; yaprak boyu $6,15 \mathrm{~cm}$; sonbaharda büyüme şekli 4,74; bitki çapı $11,49 \mathrm{~cm}$; ilkbaharda büyüme zamanı 5,10; salkım oluşturma eğilimi 4,15; salkım boyu 5,81 cm; son boğum uzunluğu 17,68 cm; yeşil ot verimi 3,57 olarak gözlemlenmiş veya ölçülmüştür. Bu projede elde edilen değerler çalışmaların uzun süreli yapılmasıyla daha sağlıklı olacaktır. Çünkü projeyle incelenen çok yıllık bitkilerin bitkisel özellikleri her yıl farklılık gösterebiliyor. Burada önemli olan verim ve kaliteyi uzun y1llar devam ettirebilmektir.

F. valesiaca türünde yaprak dokusunun ince-orta kalınlıkta olması, çim kalitesi yüksek olan genotiplerin olması, mavi-yeşil renkli, kısa boylu ve yoğunluğu yüksek, genotiplerin olmasından dolayı çim tipi alanlarda yeni alternatif bir tür olarak değerlendirilmesi gerektiği düşünülmektedir. 
Tablo 2. Festuca valesiaca'nın incelenen özellikler arasındaki korelasyon katsayıları (r)

\begin{tabular}{llllllllllllllll}
\hline ÇK & MR & YD & YO & BB & YE & YB & SB & ÇA & İ & BE & BBY & SBU & YOV \\
\hline
\end{tabular}

ÇK 1

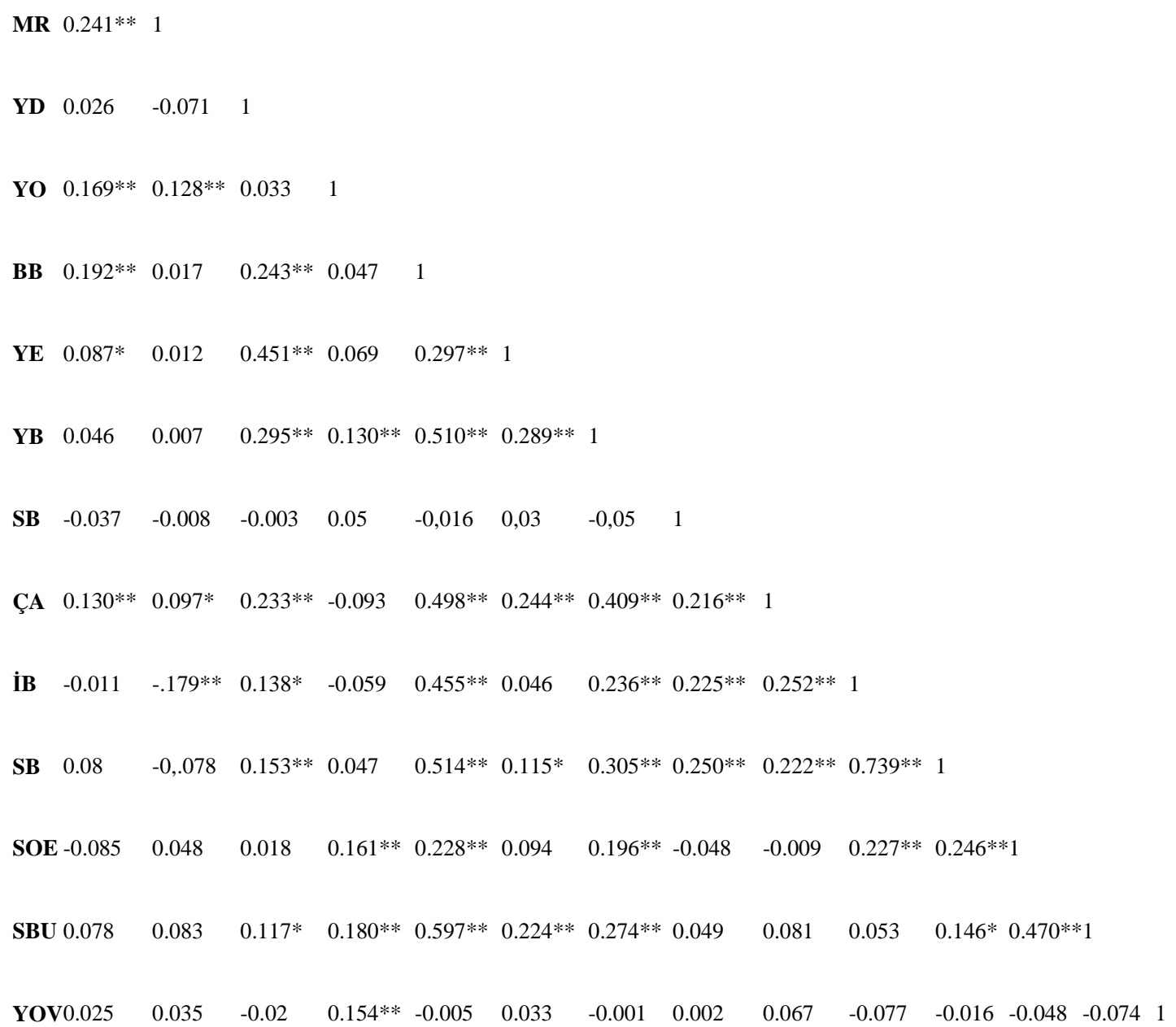

** Korelasyon 0.01 düzeyinde önemlidir. * Korelasyon 0.05 düzeyinde önemlidir. ÇK: Çim Kalitesi (1-9), MR: Mevsimsel renk değiş̧imi (19) YD:Yaprak dokusu (1-9), YO:Yoğunluk (1-9), BB:Bitki boyu (cm), YE:Yaprak eni (cm), YB:Yaprak boyu (cm), SB:Sonbaharda büyüme şekli (1-9), ÇA:Bitki Çapı (cm), İB:İlk baharda yeniden büyüme zamanı (1-9), SOE:Salkım oluşturma eğilimi (1-9), SB:Salkım boyu (cm),

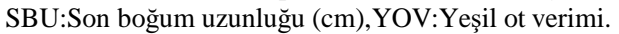

Festuca valesiaca genotiplerinde incelenen bitkisel özellikler arasındaki ikili ilişkiler Tablo 2.' de görülmektedir. Tablo 2. incelendiğinde görüleceği gibi çim kalitesinde 0.01 düzeyinde mevsimsel renk değişimi, yoğunluk, bitki boyu ve bitki çapı ile olumlu ve önemli ilişki vardır. Yine çim kalitesi ile 0.05 düzeyinde yaprak eni ile olumlu ve önemli ilişki vardır. Çim kalitesi yeşil alanlarda kullanılabilme imkanları araştırılan çim bitkileri için önemli bir özelliktir. Yeşil ot verimi ile yoğunluk arasında 0.01 düzeyinde olumlu ve önemli ilişki saptanmıştir. 


\section{SONUÇLAR VE ÖNERİLER}

Türkiye florası yem bitkileri ıslahı yönünden büyük bir genetik potansiyele sahip olup çeşit geliştirmek için Festuca türlerinin çeşitliliği bakımından oldukça zengindir. Yerli genotiplerin seçilmesi hem ot hem de çim tipi amaçlarına uygun ıslah çalışmalarda kullanılması önemlidir. Ülkemizin iklim ve toprak yapısına uygun, verimi ve kalitesi yüksek, hastalık ve zararlılarına dayanıklı çeşitlerin geliştirilmesine öncülük edebilecektir. Ayrıca Türkiye orjinli genotiplerin bu tür çalı̧̧malarda değerlendirilmesi zaman içerisinden doğal kaynaklarımızın yok olmasını engelleyerek genetik materyallerimizin korunmasına katkı sağlayacaktır.

Türkiye' de yem açığını kapatılması ve yeşil alanlarda ihtiyaç duyulan özelliklerin karşılanması için yeni çeşitlerin geliş̧irilmesinde doğal kaynağımız olan yumak türlerinin kullanılması büyük önem arz etmektedir. Mevcut çalışmada Türkiye'nin farklı bölgelerinden toplanmış 50 adet Festuca genotipinin morfolojik ve tarımsal özellikleri belirlenmiş ve ümit vadetmektedir. Bu genotiplerde hem morfolojik hem de genetik akrabalık yakınlıkları incelenmiştir. Yapılan her iki analiz sonucunda da genetik çeşitliliğin yüksek olduğu belirlenmiştir.

Çalışmada elde edilen sonuçlar geniş coğrafik yapıya sahip bölgelerde mevcut varyasyonun kullanılması ile genetik tabanı genişletmek ve mevcut varyasyonun boyutunu öğrenmek ıslah çalışmalarında gerekli olduğunu göstermektedir. Bu anlamda yapılan çalışma ülkemizde bulunan Festuca türlerinin morfolojik genetik yapısı bilinen biyolojik çeşitliliğinin belirlenmesi ve henüz ülkemiz için yeterli olmayan yerel çeşit ihtiyacımızın giderilmesi için hizmet edecektir. Ülkemiz gen kaynağı olarak Festuca türlerinin ülkemiz ekonomisine de dahil edilmesi ile ithalatın önüne geçilmiş olacak, bu konuda eksikliğin giderilmesi yanında ülke ekonomisine zirai açıdan önemli bir katkı sağlayacaktır. Ayrıca bu çalışmanın ileride yapılacak benzer karakterizasyon, seleksiyon ve ıslah çalışmalarına önemli katkı sağlayacağı düşünülmektedir.

\section{TEŞEKKÜR}

Yazarlar, bu çalışmanın gerçekleştirilmesinde her türlü katkı ve desteklerini sağlayan TÜBİTAK'a (TOVAK 1130919 no'lu) proje tesekkür eder.

\section{KAYNAKLAR}

[1] Güner, A. ve Aslan, S., (2012), Türkiye bitkileri listesi:(damarlı bitkiler), Nezahat Gökyiğit Botanik Bahçesi Yayınları, p, 74-79.

[2] Budak, Ü. (2003) Karanlıkdere Vadisi (Şefaatli-Yerköy-Yozgat) Florası. Erciyes Üniversitesi, Fen Bilimleri Enstitüsü, Yüksek Lisans Tezi, 29-44

[3] Şehirali, S., Özgen, M., Karagöz, A., Sürek, M., Adak, S., Güvenç, İ., Tan, A., Burak, M., Kaymak, H.Ç. ve Kenar. D. (2005) Bitki genetik kaynaklarının korunma ve kullanımı. TMMOB Ziraat Mühendisleri Odası VI. Teknik Kongresi. Cilt 1. Kozan Ofset, Ankara, 253- 273.

[4] Davis, PH. (1985). Flora of Turkey and East Aegean Islands, Vol: 10 (Gramineae), Edinburg, 173-175

[5] Avcığlu, R. (1997). Çim Tekniği (Yeşil Alanların Ekimi, Dikimi ve Bakımı). Ege Üniversitesi Matbaası, Bornova, İzmir, 271

[6] Tamkoç, A., Avcı, M.A. ve Özköse, A. (2009). Doğal florada bulunan çok yıllık çim (Lolium perenne L.) genotiplerinin toplanması ve islah amaçlı kullanılması. $106 \mathrm{O} 159$ nolu TUBİTAK Projesi Kesin Sonuç Raporu.

[7] Tamkoç, A., Avcı, M.A. ve Özköse, A. (2013). Doğal Floradan Toplanarak Bazı Bitkisel Özellikleri Belirlenmiş Çok Yıllık Çim (Lolium perenne L.) Genotiplerinin Sentetik Çeşit Islahı Yöntemiyle Geliştirilmesi, $110 \mathrm{O} 312$ nolu TUBİTAK Projesi Kesin Sonuç Raporu. 